\title{
Continuous use of intermittent bladder catheterization - can social support contribute?
}

\author{
Marjoyre Anne Lindozo Lopes ${ }^{1}$ \\ Elenice Dias Ribeiro de Paula Lima²
}

\begin{abstract}
Objective: to investigate the factors affecting the adequate continuous use of intermittent catheterization and its relation with social support. Method: sectional, descriptive and correlational study involving 49 patients with neuropathic bladder caused by spinal cord injury. Results: almost all (92\%) participants continued the intermittent catheterization, but $46.9 \%$ made some changes in the technique. The complications (28.6\% of the sample) were mainly infection and vesicolithiasis. There were high scores for social support in relation to people that were part of the patient's social support. Conclusion: All of them noticed great support from the family, but not from the society in general. The difficulties were related to the lack of equipment and inadequate infrastructure, leading to changes that increased urologic complications.
\end{abstract}

Descriptors: Urinary Bladder, Neurogenic; Urinary Catheterization; Social Support.

${ }^{1}$ MSc, RN, Rede Sarah de Hospitais de Reabilitação, Belo Horizonte, MG, Brazil.

${ }^{2}$ PhD, Assistant Professor, Escola de Enfermagem, Universidade Federal de Minas Gerais, Belo Horizonte, MG, Brazil.

Corresponding Author:

Marjoyre Anne Lindozo Lopes

Av. Amazonas, 5953

Bairro: Gameleira

CEP: 30510-000, Belo Horizonte, MG, Brasil

E-mail: marjoyrelindozo@sarah.br
Copyright $\odot 2014$ Revista Latino-Americana de Enfermagem This is an Open Access article distributed under the terms of the Creative Commons Attribution Non-Commercial License (CC BY-NC).

This license lets others distribute, remix, tweak, and build upon your work non-commercially, and although their new works must also acknowledge you and be non-commercial, they don't have to license their derivative works on the same terms. 


\section{Introduction}

The clean intermittent bladder catheterization (CIC) has revolutionized the care of neuropathic bladder, promoting better quality of life and reduction of mortality due to kidney complications in patients with spinal cord injury ${ }^{(1-2)}$. It is preferred to the permanent bladder catheters because it has reduced risk of chronic urinary infections and sepsis; it is easy to use and cost effective ${ }^{(1,3-4)}$. However, it demands regularity, availability, discipline and adherence, and without these things it can have adverse events in up to $56 \%$ of the $\operatorname{cases}^{(5)}$.

The most frequent complication of the CIC is the urinary tract infection, which can reach up to the similar rates of the aseptic technique if the patient disregards the care required ${ }^{(6-8)}$. The CIC practice involves specific challenges for patients, but there is evidence that a good guidance, the adherence on the part of patients and the use of appropriate equipment help prevent complications $^{(1,7)}$.

In our clinic, it was observed that many patients do not follow the instructions when they return to their homes, although showing interest and good learning during the CIC training. They change the prescribed regularity, neglect or completely disregard the technique, which increases the risk of infections and other urinary complications. In the search for an effective intervention to improve the adherence of patients to the instructions received, this work was developed to identify factors related to this problem.

In the last decades, there has been increasing interest in the role of social support in the health area. Several studies have shown the importance of social support in the recovery of diseases or traumas and in the maintenance of health(9-10). Given that no research investigating the social support to the continuous use of the CIC was found, it was proposed to also investigate this variable and the concept of social support adopted was people's perception of the care available, of the care and assistance provided by others and of being part of a social support network ${ }^{(11)}$.

The following objectives were established: (1) to investigate the factors affecting the adequate continuous use of the CIC; and (2) to determine whether there is a significant relation between the social support and the continuous use of the CIC.

To better understand the correlation between these variables will certainly contribute to the care and the monitoring of people with neuropathic bladder.

\section{Method}

This sectional, descriptive and correlational study was carried out at the Sarah Rehabilitation Hospitals Network, Belo Horizonte unit, in the state of Minas Gerais, Brazil, which develops rehabilitation activities for diseases that affect the musculoskeletal system through interdisciplinary care.

The sample consisted of 49 adult patients with spinal cord injury, who had undergone the CIC during rehabilitation and returned to the care of the team between November 2011 and February 2012. The value of the sample was calculated by considering Pearson's linear correlation coefficient, with significance level of $5 \%$, test power of at least $80 \%$, and average power effect power $(r=0.40)$.

Prior to data collection, the research was approved by the Ethic Committee of the Sarah Network n. 669 and the UFMG ETIC 0046.0.203.000-11. The patients were invited to participate and explained about the research. Those who agreed to participate signed the Informed Consent Form.

Data were collected through individual interviews and inserted into the program SPSS-version 13.0, in which they were handled and analyzed by means of descriptive and correlational statistic. The correlation analysis between the social support and the sociodemographic and clinical variables was performed through the Spearman correlation. The Kruskal-Wallis non-parametric test was used to compare the results between the group that maintained the use of the CIC and the group that disregarded it.

Data were collected with the use of the following instruments: (1) Sociodemographic form for collection of personal details of the patients, such as age, gender, level of education, marital status and cause of the spinal cord injury. (2) Bladder rehabilitation monitoring questionnaire, for information about the factors that hindered or supported the continuous use of the CIC at home. (3) Social Support Network Inventory (SSNI - Portuguese version), to investigate the social support received by the patient.

The SSNI (Social Support Network Inventory) ${ }^{(11)}$ enables the evaluation of people's satisfaction with the support received, that is, with the way their needs have been met by those with whom they interact socially, either within the family or the community. This instrument allows investigating the composition of their social network and, through 10 closed items and 1 open item, to investigate the existence of practical and 
emotional support. Each item allows a score from 0 to 5, which indicates 'no support' or 'maximum support'. The higher the score, the higher is the support that the patient considers to receive. The SSNI is a widely used, reliable, valid, simple and easy to be applied instrument. It was translated, adapted and validated in Brazil among women undergoing breast cancer treatment and patients with diabetes mellitus, showing good validity and reliability with a Cronbach alpha of $0.90^{(12-13)}$. In the present study, the same result was found, confirming excellent internal consistence of the SSNI - Portuguese version.

\section{Results}

The sample was predominantly young and single men, with average age of $33.9(S D=12.64)$. Most of them had low level of education and low family income. Almost $80 \%$ of them had suffered traumatic injuries, with predominance of motor vehicle accident injuries (51.0\%). After the injury, only $6.0 \%$ returned to perform paid activities. More details are presented in Table 1.

Almost half of the patients (44.9\%) did not use the CIC before receiving treatment at the rehabilitation service and, after this period, only 4 (8.2\%) did not continue this bladder emptying technique. Among these 4 who interrupted the use of the CIC, 2 thought to have had neurological improvement and no more need for catheterization, 1 lived in a nursing home and reported not having social support, and another stopped following medical advice, in order to treat urinary infection. These latter two started to use indwelling catheters.

Most of them, $32(65.3 \%)$, performed selfcatheterization, and 13 (26.5\%) performed assisted CIC, because they needed the help of someone else. The average bladder emptying by CIC was 4 a day.

The equipment needed for catheterization is an important factor to the continuous use of this method by patients. However, it is costly, mainly due to the low family income of most of them. Only 13 (26.5\%) fully received the equipment necessary from the Healthcare System. In addition to the equipment required, $33(73.5 \%)$ needed to make use of anticholinergic medication, but only $18.4 \%$ received them for free, and only these used the medication as prescribed.

The problems for a proper continuous use of the CIC were identified and presented in Table 2. The most frequent were related to the difficulties and changes in the performance of the technique.
Table 1 - Sociodemographic information. Belo Horizonte, MG, Brazil, 2011

\begin{tabular}{|c|c|c|}
\hline Variables & $\mathbf{n}$ & $\%$ \\
\hline \multicolumn{3}{|l|}{ Gender } \\
\hline Male & 40 & 81.6 \\
\hline Female & 9 & 18.4 \\
\hline \multicolumn{3}{|l|}{ Educational level } \\
\hline Illiterate & 1 & 2.0 \\
\hline$<9$ years of study & 23 & 46.9 \\
\hline $9-12$ years of study & 9 & 18.4 \\
\hline$>12$ years of study & 15 & 32.6 \\
\hline \multicolumn{3}{|l|}{ Employment status } \\
\hline Employed & 3 & 6.1 \\
\hline Unemployed & 11 & 22.5 \\
\hline Pension & 28 & 57.1 \\
\hline Retired & 7 & 14.3 \\
\hline \multicolumn{3}{|l|}{ Income* } \\
\hline$<1$ minimum wage & 1 & 2.0 \\
\hline 1 minimum wage & 9 & 18.4 \\
\hline $2-4$ times the minimum wage & 31 & 63.3 \\
\hline $5-9$ times the minimum wage & 5 & 10.2 \\
\hline$>10$ times the minimum wage & 3 & 6.1 \\
\hline \multicolumn{3}{|l|}{ Diagnosis } \\
\hline \multicolumn{3}{|l|}{ Paraplegia } \\
\hline Traumatic & 23 & 46.9 \\
\hline Not traumatic & 8 & 16.3 \\
\hline \multicolumn{3}{|l|}{ Tetraplegia } \\
\hline Traumatic & 16 & 32.7 \\
\hline TPL non traumatic & 2 & 4.1 \\
\hline \multicolumn{3}{|l|}{ Cause } \\
\hline Automotive & 5 & 10.2 \\
\hline Motorcycle & 10 & 20.4 \\
\hline Projectile from a firearm & 10 & 20.4 \\
\hline Diving into shallow water & 4 & 8.2 \\
\hline Object falling on the chest & 3 & 6.1 \\
\hline Falling from a height & 7 & 14.3 \\
\hline Pathologies & 10 & 20.4 \\
\hline
\end{tabular}

Table 2 - Problems in the use of the CIC. Belo Horizonte, MG, Brazil, 2011

\begin{tabular}{lcc}
\multicolumn{1}{c}{ Variables } & $\mathbf{n}$ & $\%$ \\
\hline $\begin{array}{l}\text { Changes in the technique } \\
\text { Yes }\end{array}$ & 23 & 46.9 \\
$\begin{array}{l}\text { Need for help } \\
\text { Yes } \\
\text { Difficulties in performing } \\
\quad \text { Yes } \\
\text { Urologic complication } \\
\quad \text { Yes }\end{array}$ & 13 & 26.5 \\
\hline
\end{tabular}

The technique changes were related to the prescribed intervals, to the lack of hand or genitalia 
sanitation before the catheterization and to the lack of use of lubricants to avoid hurting the urethra. The lack of infrastructure and the financial limitation for purchasing the required equipment were the main obstacles mentioned to perform the correct technique. For example, they complained about the lack of adequate public toilettes, the existence of architectural obstacles everywhere, or the costs of the equipment (such as lubricants) for an already so compromised family budget.

Both the changes in the technique and the complications may interfere and cause discomfort or pain during catheterization, a feeling that was reported by half of the sample. The most common complication was vesicolithiasis (28.2\%), followed by hydronephrosis or ureteral dilation in $18.4 \%$ of the cases. Urinary infection was present in $20.0 \%$ of the sample, but this had already been diagnosed before the beginning of the study. Urethral trauma occurred in 6 patients $(12.2 \%)$ and urinary leakage during the intervals was mentioned by approximately $33.0 \%$ of the patients, even with the use of anticholinergic medications, in periods when patients increased fluid intake.

There was no statistically significant difference between social support and continuous use of the CIC. All patients presented high scores in the SSNI, which ranged from 4.0 to 5.0 on a scale with possible range from 0 (no support) to 5 (excellent support). The high total average indicated that the patients perceived to have a good support from the people who were part of their social network, as shown in Table 3.

Table 3 - Measurements of Social Support Network Inventory. Belo Horizonte, MG, Brazil, 2011

\begin{tabular}{|c|c|c|c|}
\hline \multirow{2}{*}{$\begin{array}{c}\text { Social Support } \\
\text { Network Inventory }\end{array}$} & \multicolumn{2}{|c|}{ Interruption of catheterization } & \multirow{2}{*}{$\begin{array}{l}\text { Total } \\
(n=48)\end{array}$} \\
\hline & No $(n=45)$ & Yes $(n=3)$ & \\
\hline Average (SD) & $4.70(0.33)$ & $4.68(0.55)$ & $4.70(0.34)$ \\
\hline
\end{tabular}

Despite the high perception of support, the data showed a quite reduced social network, ranging from 1 to 3 people, always within the family and mainly mothers or wives. The results also showed that the patients who were married had little higher scores of social support, but with no statistically significance when compared to the unmarried. The SSNI items that presented the highest scores were "Emotional support and "Practical support", indicating that these mothers and wives did not only provided emotional support, but also were always available to help the catheterization and other practical needs of the patients' daily lives.
The nonparametric Kruskal-Wallis test was used to compare the medians of each relevant variable. The only variable that showed significant difference was gender, showing that women had higher scores for social support than men $(p<0.05)$.

To evaluate the average for Social Support with the quantitative variables, the Spearman correlation test was used. There was poor correlation for 'age' and moderate correlation for 'number of family members', indicating that the social support increased in so far as the age of patients and number of immediate family members increased. In relation to the other variables, there was no significant correlation.

\section{Discussion}

Similarly to the data found throughout the world, the results showed a predominance of young men with injuries resulting from trauma, especially caused by motor vehicle accidents ${ }^{(14-15)}$. The World Health Organization has warned for traffic violence, urging the public healthcare services to act towards the effective and persistent prevention. It is estimated that each year about 50 million people around the world are injured in motor vehicle Accidents, and estimates point out that this number will increase around $65 \%$ in the next 20 years if serious prevention measures are not taken ${ }^{(15)}$

Half of the sample had none or low level of education and limited family income. These patients were mainly labor workers and the job prospects after the injury were more difficult due to the low level of education. During data collection, with the exception of three patients, none of them were performing a paid job. Besides the financial burden on the family, this situation also causes an overload to the Social Security Service, especially when considering the characteristics of the chronicity of the injury. The economic consequences that the low employability and no return to work are harmful, not only to the person and their families, but also to the country's economy ${ }^{(16)}$. In addition to the economic and physical burden, it is estimated that approximately half of the population with spinal cord injury suffer from mental health problems, either depression, anxiety, clinical stress or post-trauma disorder, which shows the high probability of comorbidities among these people and the great need for social support $(2,16)$.

The results showed excellent social support from those people that patients considered being part of their social network; however, this support network 
was quite limited in all the cases, ranging from one to three people, usually mothers or wives. Despite the emotional and practical support, this limited network resulted in the limitation or lack of supply to continue the CIC in those patients that had interrupted it. There was the support of the family, but not the support of the society concerning the provision of infrastructure, availability of the equipment required for the CIC or even job opportunities to allow people to have financial independence. The study showed that, although most patients continue with the CIC practice, several changes to the technique were made due to the lack of equipment, which increased the risk of urologic complications.

There was no statistically significant difference between the two groups concerning social support. However, it is important to consider that the size of the sample does not have enough power to detect any difference between the groups of patients. Only four of them did not continue the CIC and, of these, one refused to answer the SSNI due to not having any social support, and this was the exact reason for the exchange of the CIC for the permanent catheterization.

Reinforcing the data from other studies, the main complications were the urinary infection and the vesicolithiasis. Preventing the overfilling of the bladder is one of the most important prevention measures for both complications. The latter is commonly caused by urinary stasis, which occurs when the patient does not follow the intervals between catheterizations, or do not follow the recommended water intake, often significantly reducing it in an attempt to need less catheterizations per day ${ }^{(1)}$. The study showed that this occurred when patients left home because they were faced with difficulties such as lack of toilettes, or hygiene in public places, besides architectural obstacles, a problem that ended up causing them to isolate themselves socially.

Urethral trauma, which occurred in six patients, is another common complication among users of intermittent catheterization, specially the male. The lubrication and the careful insertion of the catheter and the use of hydrophilic catheters are important factors to minimize the risk of this complication. Among the patients that presented this problem, the lack of adequate equipment was associated with the development of urethral trauma.

A frequent problem among the patients with neuropathic bladder, which was mentioned by $33 \%$ of the sample, is the urinary incontinence during the intervals. The use of anticholinergic medications is important for the control of this problem, but only $18.4 \%$ of the sample used this medication due to not having conditions to buy it, nor receiving it through the Social Security.

\section{Conclusion}

The results of this study highlighted the importance of social support for the continuous use of the CIC. The support provided by those who were part of the social support network to the patient was excellent and, probably due to this reason, most of the patients did not interrupt the technique. However, the study showed the need of support also by the social system. The need of job and qualification opportunities is added to the need of adequate infrastructure so that people with spinal cord injury is not only socially reintegrated, but also to have a productive life once again. The lack of infrastructure leads to social isolation, because in addition to hindering the mobility, it also hinders the provision of specific care for bladder emptying. The cost for the required equipment for catheterization is a financial burden for more than $70 \%$ of the patients, who then made several changes to the technique, putting their health at risk.

The management of neuropathic bladder is a challenge for patients, and nurses should encourage them to perform bladder rehabilitation and continue using the catheter after being released from hospital. The CIC is the preferred way of emptying the bladder, being considered the golden technique, because it has less complication and better results, and the most frequent measures to prevent complications are the good education, the good patient adherence, the use of appropriate equipment and the application of good catheterization technique.

The importance of social support for the adherence of patients to chronic treatments has been demonstrated in various studies involving other populations; this study contributed with information about the relation between social support and the continuous use of bladder catheterization in patients with spinal cord injury; and it also investigated factors related to the continuous use of the CIC in this population, thereby contributing for nurses to adequately intervene in the prevention of urinary complications of patients with neuropathic bladder, promoting their quality of life and social inclusion, and helping them to regain their autonomy and improve their self-esteem.

This study has the limitations of a correlational research. Although it suggests the relationship between 
variables, this method does not allow casual inferences to be made. In addition, a larger sample size would allow a deeper investigation of the variables studied. It is recommended that other studies are conducted in this area in order to establish a higher degree of accuracy in relation to the problem of the continuous use of the CIC by patients with neuropathic bladder.

\section{References}

1. Di Benedetto P. Clean intermittent self-catheterization in neuro-urology. Eur J Phys Rehabil Med. 2011;47(4):651-9.

2. Cameron AP, Wallner $L P$, Tate DG, Sarma AV, Rodriguez GM, Clemens JQ. Bladder management after spinal cord injury in the United States 1972 to 2005. J Urol. 2010;184:213-17.

3. Gormley EA. Urologic Complications of the Neurogenic Bladder. Urologic Clin North Am. 2010;37(4):601-7.

4. Samson G, Cardenas DD. Neurogenic Bladder in Spinal Cord Injury. Phys Med Rehabil Clin North Am.2007;18(2):255-74.

5. Wilde $\mathrm{MH}$, Brasch J, Zhang Y. A qualitative descriptive study of self-management issues in people with longterm intermittent urinary catheters. J Adv Nurs. 2011;67(6):1254-63.

6. International Continence Society. Documents. [acesso 28 nov 2009]. Disponível em: http://www.icsoffice.org 7. Singh R, Rohilla RK, Sangwan K, Siwach R, Magu NK, Sangwan SS. Bladder management methods and urological complications in spinal cord injury patients. Indian J Orthop. 2011; 45(2):141-7.

8. Afsar SI, Yemisci OU, Cosar SNS, Cetin N. Compliance with clean intermittent catheterization in spinal cord injury patients: a long-term follow-up study. Spinal Cord. 2013;51: 645-9.

9. Dimatteo MR. Social Support and Patient Adherence to Medical Treatment: a Meta-Analysis. Health Psychology. 2004;23(2):207-18.

10. Müller R, Peter C, Cieza A, Geyh S. The role of social support and social skills in people with spinal cord injury--a systematic review of the literature. Spinal Cord. 2012;50(2):94-106.

11. Flaherty JA, Gaviria FM, Pathak DS. The measurement of social support: The social support network inventory. Compr Psychiatry.1983;24:521-9.

12. Lima EDRP, Norman ME, Lima, AP. Translation and Adaptation of the Social Support Network Inventory in Brazil. J Nurs Scholarship. 2005; 37(3):258-60.
13. Gomes-Villas Boas LC, Foss MC, Freitas MCF, Pace

AE. Relação entre apoio social, adesão aos tratamentos e controle metabólico de pessoas com diabetes mellitus. Rev. Latino-Am. Enfermagem. 2012;20(1):52-8.

14. Center. Annual Statistical Reports. 2011. [acesso 13 nov 2012]. Disponível em: https://www.nscisc.uab.edu/ reports.aspx

15. Década de ação para a segurança no trânsito 2011-2020. [acesso 13 nov 2012]. Disponível em: http://portal.saude.gov.br/portal/saude/profissional/ visualizar_texto.cfm?idtxt

16. Lasprilla JCA, Plaza SLO, Drew A, Romero JL, Pizarro $J A$, Francis $K$, et. al. Family needs and psychosocial functioning of caregivers of individuals with spinal cord injury from Colombia, South America. NeuroReabilitation. 2010;37:83-93. 